\title{
Prisión perpetua revisable: El caso colombiano desde la perspectiva constitucional
}

\author{
Reviewable Life Sentences: The Colombian Case in a \\ Constitutional Perspectiv
}

https://doi.org/10.15332/iust.v0i15.2086

\begin{abstract}
Daniel Montero Zendejas
Doctor en Derecho; profesor-investigador de tiempo completo; titular "C", Facultad de Derecho y Ciencias Sociales de la Universidad Autónoma del Estado de Morelos; miembro del Sistema Nacional de Investigadores SNI (nivel II) de CONACYT; estancias de posgrado en la Universidad Católica del Uruguay y en la Universidad de Salerno en Italia.

Correo electrónico:damoz7777@yahoo.com.mx
\end{abstract}

María Fernanda Maldonado Arcón

Abogada por la Universidad Libre; estudiante de Maestría en Derecho con profundización en Derecho Penal de la Universidad Nacional de Colombia; especialista en Instituciones Jurídico Penales por la Universidad Nacional de Colombia: investigadora de la "Escuela de Derecho Penal "Nullum Crimen Sine Lege" de la Universidad Nacional de Colombia; categoría A en Colciencias 2015, adscritos al Instituto de Investigaciones Jurídico Sociales, Gerardo Molina - UNIJUS.

Correo electrónico: mfmaldonadoa@unal.edu.co

Filiberto Eduardo R. Manrique Molina

Director de Medición y Evaluación de Acceso a los Derechos Humanos en el CIIDHLEX México; doctorando en la Facultad de Derecho y Ciencias Sociales de la Universidad Autónoma del Estado de Morelos; miembro del grupo de investigación "Escuela de Derecho Penal "Nullum Crimen Sine Lege" de la Universidad Nacional de Colombia.

Correo electrónico: filiberto.manriquemol@uaem.edu.mx

\begin{abstract}
Resumen
El presente artículo se ocupa del análisis de la figura jurídica de la prisión perpetua revisable, de acuerdo con sus antecedentes doctrinarios y su aplicabilidad en el derecho comparado, específicamente en países como Inglaterra, España, China, EE.UU., entre otros. Adicionalmente, se hace un estudio jurisprudencial de los casos más relevantes sometidos a consideración de Cortes internacionales, tal es el caso del Tribunal Europeo de Derechos Humanos y los Altos Tribunales de Austria, Suiza y Alemania, donde es sujeto de revisión la pena de prisión perpetua después de cumplida la condena por un determinado tiempo. Por último, se estudia la prohibición dentro del ordenamiento jurídico colombiano de la cadena perpetua por mandato constitucional y por disposición de tratados internacionales ratificados en Colombia, junto con el precedente jurisprudencial establecido por la Corte Constitucional y la Corte Suprema de Justicia.
\end{abstract}

Palabras clave: Prisión perpetua revisable, dignidad humana, constitución, condena, pena, justicia, derechos humanos, libertad. 


\section{Abstract}

This article analyzes the legal concept of reviewable life sentences, considering doctrinal precedents and the concept's applicability in comparative law, in such countries as England, Spain, China, the United States, and others. The article also includes a legal study of the most relevant cases presented to international tribunals, like the European Human Rights Court and the Austrian, Swiss, and German High Courts, where life imprisonment sentences are subject to review after partial completion. Finally, the article analyzes the prohibition of life imprisonment in Colombia that stems from a constitutional mandate as well as from international-treaty commitments, and the legal precedents established by the country's Constitutional Court and Supreme Court.

Keywords: Reviewable life sentence; human dignity; constitution; sentencing; punishment; justice; human rights; freedom.

\section{Résumé}

Cet article traite de l'analyse de la figure légale de la prison perpétuelle révisable en fonction de son contexte doctrinal et de son applicabilité en droit comparé, notamment dans des pays comme l'Angleterre, l'Espagne, la Chine, les États-Unis, entre autres. En outre, une étude jurisprudentielle des cas les plus pertinents soumis à l'examen des tribunaux internationaux est menée, comme la Cour européenne des droits de l'homme et les tribunaux d'Autriche, de Suisse et d'Allemagne, où la peine de réclusion à perpétuité est soumise à révision. après avoir purgé la peine pendant un certain temps. Enfin, l'interdiction dans le système juridique colombien d'emprisonnement à vie par mandat constitutionnel et par la disposition des traités internationaux ratifiés en Colombie est étudiée, ainsi que le précédent jurisprudentiel établi par la Cour constitutionnelle et la Cour suprême de justice.

Mots-clés: Prison perpétuelle révisable, dignité humaine, constitution, phrase, phrase. 


\title{
Prisión perpetua revisable: El caso colombiano desde la perspectiva constitucional*
}

\author{
Daniel Montero Zendejas \\ María Fernanda Maldonado Arcón \\ Filiberto Eduardo R. Manrique Molina
}

La cadena perpetua transforma la luz en sombras.

\begin{abstract}
(Frase de la carta escrita por 310 reclusos italianos condenados a la prisión permanente revisable, dirigida al presidente de la República Giorgio Napolitano).
\end{abstract}

\section{INTRODUCCIÓN}

El siguiente artículo se ocupa del análisis de la figura jurídica de la prisión perpetua revisable desde la perspectiva constitucional, teniendo en cuenta sus antecedentes doctrinarios y su aplicabilidad en el derecho comparado, en cuanto a los antecedentes internacionales del castigo. Nos remontamos en primer lugar a la historia del castigo, desde la aplicación de la ley del Talión, que se recogía en la Ley de las XII Tablas del derecho romano y en el famoso Código de Hammurabi. En cuanto a los antecedentes de la prisión perpetua revisable se hará mención a sus inicios. Estos se remontan a las primeras prisiones de Europa, afianzándose la cárcel como castigo a partir del siglo XVIII. De igual forma, se analizarán las diferentes concepciones de la cárcel como castigo en la época del Renacimiento como forma disciplinaria y de control social. Adicionalmente, se hace un recorrido por la concepción de castigo propuesto por grandes pensadores como Beccaria, Foucault, Zaffaron y Ferrajoli.

También se hará un recuento histórico del antecedente de la prisión perpetua en Colombia, instituido en el Código Penal de 1890, y que posteriormente fue abolido mediante el Acto Legislativo No. 3 de 1910. En Colombia desde aquella carta política del siglo XIX se considera que no ha existido cadena perpetua. En cuanto a la revisión doctrinaria a nivel internacional se hará un recorrido sobre algunos países donde la prisión perpetua está prohibida expresamente por mandato constitucional; en otros

Artículo de investigación resultado de trabajo cooperado entre: Grupo de Investigación: "Escuela de Derecho Penal NULLUM CRIMEN SINE LEGE UN" de la Facultad de Derecho, Ciencias Políticas y Sociales de la Universidad Nacional de Colombia, Código COL0078909, reconocido y clasificado en categoría A Colciencias 2015, y el Doctorado en Derecho y Globalización de la Universidad Autónoma del Estado de Morelos, México. 
donde se prohíbe su aplicación por considerarse inconstitucional en decisiones de sus altos tribunales de justicia.

De igual forma, también se hará mención de algunos países de Europa, como por ejemplo España, donde la prisión perpetua ya no existe como pena, pero que en algún momento existió en su legislación. Adicionalmente, se señalarán concretamente los países donde la prisión perpetua existe en la actualidad y su forma de utilización para delitos graves, pero siempre con la fijación de un plazo a partir del cual el condenado puede acceder a la libertad condicional, lo que se conoce hoy en día como prisión perpetua revisable en estricto sentido. Dentro de los países donde se aplica en la actualidad la prisión perpetua revisable se estudiará el caso de Alemania, donde la revisión de la condena de prisión revisable es un mandato, no la excepción. La principal condición para acceder a la libertad condicional desde la prisión revisable en ese país es haber cumplido (15) quince años de condena en la cárcel. Por último, se profundizará en ciertos países donde la prisión perpetua es aplicada sin posibilidad de libertad condicional. En estos casos, la pena tiene una duración equivalente a la vida natural de una persona, como sucede actualmente en Estados Unidos e Inglaterra.

Asimismo, se realizará un estudio jurisprudencial de los casos más relevantes sometidos a consideración de Cortes internacionales, en países como Alemania, Austria, Suiza, Francia e Italia. Además, se analizan varios fallos de tribunales internacionales en cuanto a las limitaciones que impone el Estatuto de Roma a la prisión perpetua, sometidos a consideración del Tribunal Europeo de Derechos Humanos, junto con el precedente jurisprudencial de inconstitucionalidad de la cadena perpetua implementado por la Suprema Corte de Justicia de México y el Tribunal Constitucional del Perú como modelos en América Latina.

En cuanto al ordenamiento jurídico de Colombia, se estudiará la prohibición de la cadena perpetua por mandato constitucional, señalando un criterio general de limitaciones jurídicas concretamente en lo que se refiere al artículo 11, 12 y 34 de la carta política. Este último establece que se prohíben las penas de destierro, prisión perpetua y confiscación. Teniendo en cuenta lo anterior, se revisan los principales fallos emitidos por la Corte Constitucional de Colombia, relacionados con la prohibición de la cadena perpetua desde los fines de la pena, estudiando la Sentencia hito C-596 de 1992. También, se analizará la Sentencia C-070 de 1996, según la cual la Corte establece claramente que le está vedado, por voluntad expresa del constituyente, establecer la prisión perpetua en Colombia por considerar que dentro de un Estado social de derecho en ejercicio de su esfera constitucional, deberá potenciar la dignidad humana en todos los ámbitos de la vida, incluyendo el derecho sancionatorio, aspecto en el que se articula la prevención general con la especial, en tanto contribuya con la eliminación de penas crueles violatorias de los derechos fundamentales.

Avanzando en nuestro razonamiento, dentro de la órbita constitucional, se pretende analizar el principio constitucional de proporcionalidad de las penas mediante la Sentencia C-397 del 2010 como elemento esencial del sistema punitivo de un Estado social de derecho. Al igual que el anterior principio contempla el estudio de 
la prohibición de regresividad, que opera como límite a la desmejora de los derechos en un Estado social de derecho como el colombiano, haciendo imposible su retroceso en materia de imposición de penas. De igual forma, en ejercicio de la función del ius puniendi, "la cual es la facultad que tiene el Estado para utilizar el poder punitivo e imponer penas o medidas de seguridad", (Goite, Medina, Fernández, Huertas, \& Ruiz, 2016) se establece la ponderación de la dignidad humana de forma razonable y proporcional a la hora de imponer dichas sanciones, garantizando así, el principio pro libertate, en armonía con el principio pro-homine en la ejecución de las penas. Seguidamente, se analizan los postulados del garantismo penal y sus efectos en los derechos fundamentales de los condenados, buscando promover el concepto de la pena como de última ratio.

Por último, en el presente artículo se realiza un análisis de la importancia de la política criminal eficiente y la influencia o responsabilidad de los medios de comunicación en impulsar campañas que buscan promover la implementación de la cadena perpetua para ciertos actos penales en Colombia. Por ejemplo, los delitos contra la integridad sexual de menores de edad, que en su gran mayoría generan un impacto en la ciudadanía, los movimientos sociales y la influencia que esto tiene en la implementación de la política punitiva en Colombia a través de iniciativas populares o legislativas impulsadas por casos mediáticos que afectan notablemente los procesos de resocialización del condenado, esto es, "el incorporar al individuo a la sociedad para inculcarle de una manera activa y dinámica el respeto y la conservación de los valores de una sociedad" (Huertas, López, \& Malaver, 2011).

\section{METODOLOGÍA}

La metodología seguida en el desarrollo del presente artículo se fundamenta bajo dos perspectivas, la analítica y la comparativa; la primera aborda la temática de manera razonada, cualitativa y descriptiva, centrada en una amplia revisión bibliográfica del tema, los autores, el desarrollo histórico y el contexto actual, para poder conocer los alcances y límites desde un punto de vista crítico y propositivo de la prisión perpetua revisable. Con la perspectiva comparativa se buscará analizar sistemáticamente el desarrollo doctrinal que ha tenido la prisión perpetua en diversos países de Europa y América, cuyo fin es la verificación de nuestra hipótesis, la cual se dirige a la aplicación de una justicia humana de ultima ratio.

\section{ANTECEDENTES DE LA PRISIÓN PERPETUA REVISABLE}

\section{Internacionales}

La historia del castigo hace parte de los actos cometidos en nombre del derecho penal que han dejado al descubierto la crueldad humana ejecutada durante varios siglos desde la aplicación de la Ley del Talión, reflejada de una forma clara y concisa 
en la célebre frase "ojo por ojo diente por diente" que aparecía recogida en la Ley de las XII Tablas del derecho romano y en el famoso Código de Hammurabi vigente en la antigua Mesopotamia. En la edad media aparece el derecho penal europeo, que se implementó como resultado de la fusión del derecho germánico, canónico y romano. Esta época se caracterizaba por una protección de los intereses de los monarcas, del clero y de la nobleza, implicando esto una correlativa desigualdad ante la ley. Otro rasgo característico era la inexistencia de garantías procesales y la inclusión de diferentes penas como la tortura, los malos tratos, las mutilaciones, la pena de muerte, los trabajos forzados y la confiscación de todo tipo de bienes (Pascual, 2014). Como uno de los antecedentes más importantes de la prisión perpetua revisable, se consideran las primeras prisiones de Europa, las cuales estaban destinadas a recoger vagabundos, prostitutas y jóvenes delincuentes alrededor del siglo XVI, los cuales se encontraban principalmente en las ciudades. Se considera que la cárcel como castigo se aplicó de manera formal a partir del siglo XVIII (Barros, 1995).

Por su parte, durante el renacimiento (siglos XIV y XVI) se restableció la autonomía que había perdido el hombre en la edad media, mientras se encontraba supeditado a leyes extrínsecas dentro de las cuales era tratado como objeto o cosa. Se ha dicho que la causa más grande y definida del origen de la prisión como castigo fue la conciencia adquirida de la libertad, ya que a partir de la edad moderna esta se convierte en un bien preciado, tanto filosófica como económicamente (Scimé, 1986). A partir del siglo XVIII cuando los sistemas de producción comenzaron a requerir mayor cantidad de mano de obra a la que había que disciplinar, la cárcel apareció como solución a un problema de orden social capitalista, el disciplinamiento de grandes masas no obreras necesarias y de todas las fuerzas responsables del nuevo vigor adoptado por la cárcel como forma punitiva, siendo la más importante el beneficio de tipo económico sin dejar de lado factores de orden político y de las relaciones de poder. Lo anterior es analizado por autores como Foucault, quien consideraba al castigo como algo que involucra fundamentalmente cuestiones de poder y de gobierno. La prisión empezó a ser considerada como forma social de control (Juliano y Ávila, 2012).

La prisión, entendida como instrumento de reinserción social del delincuente, pero sobre todo entendida "como un proceso moral cuya función es preservar los valores compartidos y las convenciones normativas en que se basa la vida social" (Huertas, 2009), no es concomitante con el surgimiento de la privación de la libertad como pena. Al momento de su aparición nadie pensaba en ella como otra forma de castigo o de retribución del mal causado. Por su parte, las penas de prisión perpetua en sus orígenes se aplicaban de diversas formas como amputaciones o marcaciones y se consideraban como penas a perpetuidad, porque acompañaban al individuo durante toda su vida ${ }^{1}$.

1 Es así que Carrara, al clasificar las penas aflictivas sostenía que estas podían ser delebles (como los azotes) o indelebles (como las mutilaciones) en atención a su perpetuidad. 
La pena de cadena perpetua fue rechazada por el derecho romano y por el derecho civil, por considerarla equivalente a la esclavitud y, como tal, impropia de hombres libres (Tomás, 1969). Fue admitida por el derecho canónico y se imponía a clérigos autores de ciertos delitos, a quienes se recluían perpetuamente en los monasterios, después se aplicó a los autores del delito de herejía. Del derecho canónico pasó al derecho de los Estados de la iglesia y de ellos a los demás países, de tal forma que la pena de prisión pasó de la legislación canónica a la legislación civil u ordinaria, imponiéndose con mayor fuerza durante la Inquisición. Los condenados a cadena perpetua, al no tener esperanza de alcanzar la libertad no se corregían si no que, por el contrario, persistían en sus tendencias o actitudes criminales. En defensa de las cadenas perpetuas se alegaba que recluían a las personas incorregibles, apartándolas de la sociedad, evitando de esta forma la comisión de nuevos delitos por parte de ellas, ya que ejercían un gran poder intimidatorio (García y Aguirre, 1852).

El origen de las penas de prisión perpetua se encuentra íntimamente vinculado a las penas capitales. Ya Zaffaroni señalaba el origen canónico de la prisión perpetua debido a la imposibilidad de los jueces eclesiásticos de imponer penas de muerte (Zaffaroni, 2003). Por su parte Ferrajoli afirmaba que la existencia de ciertas condenas antiguas con duración perpetua como las condenas a galeras, deportación o trabajos forzados existían desde el derecho romano. Estas podían ser impuestas de forma vitalicia al condenado alcanzando su consolidación en la edad moderna como una alternativa a la pena de muerte (Ferrajoli, 1999). A partir del siglo XVIII, a la luz de la ilustración y del iluminismo, permanecía la pena de muerte para gran cantidad de delitos ${ }^{2}$. De igual forma, el establecimiento de la prisión perpetua como pena se reflejaba en la idea abolicionista del iluminismo retratado por Víctor Hugo al decir: "Nada de verdugo donde el carcelero es suficiente"3 (Hugo, 1998). Adicionalmente, la caracterización de la racionalidad y el laicismo influyó de manera relevante en la nueva concepción del derecho penal, que se rige por la razón y guiado por principios como el de legalidad e igualdad penal (Pascual, 2014).

\section{Nacionales}

En Colombia a partir de la Constitución de 1886, la única referencia histórica de pena de muerte y cadena perpetua es la establecida en el Código Penal de 1890 y abolida según Acto Legislativo No. 3 de 1910. Por su parte, los códigos penales de 1936 y 1980 nunca establecieron penas únicas o fijas. En Colombia, desde aquella

2 Hasta ese momento las penas capitales iban precedidas por espantosos rituales de tortura que incluso continuaban ya sobre el cuerpo sin vida del delincuente.

3 La perpetuidad como pena recibiría luego profundos cuestionamientos, ya que la duración sin solución de continuidad que contempla el encierro encuentra una insuperable contradicción con sus pretendidos fines resocializadores. Es así que sus evoluciones posteriores han buscado, en cierto modo, atenuar su condición de vitalicia mediante la aplicación de regímenes carcelarios progresivos donde el paso del tiempo y factores como la buena conducta del condenado podían ocasionar que se viera beneficiado con salidas anticipadas a la vida libre. 
carta política de siglo XIX, no ha existido cadena perpetua (Melo, 2016). En cuanto a antecedentes de iniciativas legislativas recientes para implementar en Colombia la pena perpetua se encuentra la Ley 1327 del 5 de julio del 2009, la cual tuvo como finalidad someter a referendo la implantación de la prisión perpetua en Colombia.

A continuación, se cita el contenido de la mencionada iniciativa:

En relación con los delitos de homicidio doloso, violación y explotación sexual, lesiones personales agravadas y secuestro cometido contra menores de 14 años y menor de edad con discapacidad física o mental, se podrá imponer hasta la pena de prisión perpetua, de acuerdo con la ley (negrilla fuera del original).

Parágrafo. El Estado, a través del ICBF, formulará y aplicará una política de prevención tendiente a evitar la comisión de delitos contra menores de edad.

La anterior iniciativa no tuvo sustento jurídico, ya que la Constitución Política de Colombia se circunscribe a prohibir unas penas y en cuanto a las que puedan establecerse señala un criterio de exclusiones o limitaciones jurídicas (Gómez, 2010).

El artículo 11, dispone: "El derecho a la vida es inviolable. No habrá pena de muerte".

El artículo 12, ordena: "Nadie será sometido a desaparición forzada, a torturas ni a tratos o penas crueles, inhumanas o degradantes".

Y el artículo 34, establece: "Se prohíben las penas de destierro, prisión perpetua y confiscación".

El desenfoque que tuvo el mencionado proyecto de ley para promover la iniciativa del referendo fue claramente inconstitucional. Encontró su principal justificación en el artículo 208 de la Ley 599 del 2000 referente al "Acceso carnal abusivo con menor de (14) catorce años". Fue utilizado como un mecanismo promotor en temas de mayor sensibilidad y reproche social para tratar de conseguir su aprobación en las urnas, valiéndose de propaganda electoral claramente contraria al bloque de constitucionalidad vigente en Colombia.

\section{REVISIÓN EN LA DOCTRINA}

La pena de prisión perpetua revisable presenta varias denominaciones en el derecho comparado y se le menciona como: presidio perpetuo, cadena perpetua, prisión perpetua, reclusión perpetua, prisión vitalicia, ergástulo, life imprisonment, entre otros. Su aplicación y reglamentación en general no difiere demasiado en lo esencial. Existen países donde la prisión perpetua está prohibida expresamente por mandato constitucional, como en el caso de Bolivia. Otros donde tampoco se aplica, pero no por encontrarse vedada en sus normas fundamentales, sino por decisiones 
de sus altos tribunales de justicia, como Perú, por considerarla inconstitucional. En otros países como España la prisión perpetua ya no existe como pena y tampoco es mencionada actualmente en su legislación. De igual forma también se encontraron países donde la prisión perpetua existe y se utiliza habitualmente para delitos graves, pero siempre con la fijación de un plazo a partir del cual el condenado puede acceder a la libertad condicional, como es el caso de Alemania y Chile.

Por último, en ciertos países la prisión perpetua sin posibilidad de libertad condicional es una realidad y puede ser impuesta a los condenados de delitos graves. En estos casos, la pena tiene una duración equivalente a la vida natural de la persona castigada, como sucede en Estados Unidos e Inglaterra (Juliano y Ávila, 2012).

En Europa es admitida la pena de prisión perpetua revisable con muchas restricciones, incluso por el Tribunal Europeo de Derechos Humanos (TEDH), porque si bien la pena de prisión permanente es revisable en Irlanda del Norte, en Inglaterra y Gales la condena a perpetuidad se reviste de carácter indefinido de por vida (whole life order). Sin embargo, no existe en Escocia ni en Portugal, en donde la cadena perpetua se derogó muy tempranamente a finales del siglo XIX, ni en el Vaticano porque el papa Francisco la eliminó en 2013, por medio de la publicación de una iniciativa propia (motu proprio) que estableció también como pena máxima de cárcel de 30 a 35 años de duración (Gargallo, 2016). Aunque las condiciones y los tiempos de aplicación varían sustancialmente y formalmente en cada país, a continuación se mencionarán algunos países para realizar una ilustración sobre la perpetuidad penal implementada en la actualidad.

\section{Alemania}

En Alemania la imposibilidad de aplicar penas perpetuas sin limitación de tiempo se vio reafirmada en el fallo de la Corte Constitucional. Mediante una sentencia se estableció como inconstitucional una pena de prisión perpetua sin posibilidad de liberación, por ser contraria a la dignidad humana ${ }^{4}$. El mencionado organismo judicial plantea que sería incompatible el concepto de dignidad humana que el Estado desarrolla con la apropiación de la facultad del mismo para privar de la libertad a personas sin darles la posibilidad de recuperar su libertad nuevamente una vez cumplida la pena (Juliano y Ávila, 2012).

El primer caso ejemplar para estudiar la prisión revisable en ese país se remonta a la Sentencia del Tribunal Constitucional con radicado número 21.1977 que establece que el tiempo máximo de cumplimiento de una pena de prisión es de 30 años. Adicionalmente, la misma Sentencia estableció la inconstitucionalidad de una pena de prisión sin horizonte de liberación. Con ello se prohíbe la cárcel perpetua de forma explícita y se admite la pena de prisión de larga duración aplicada a los crímenes catalogados típicamente como graves. También incluye la revisión de la condena a prisión revisable como un mandato, no como excepción. La principal condición para

4 Sentencia de la Primera Sala, 21 de julio de 1977. 1BvL 14/76 del STG. 
acceder a la libertad condicional desde la prisión revisable es haber cumplido (15) quince años en la cárcel. El tribunal que rechaza la excarcelación de un reo que ha alcanzado (15) quince años de prisión debe justificar su decisión con la existencia de circunstancias de gravedad especial para fundamentar esa negativa (Gargallo, 2016).

\section{Inglaterra y Gales}

En Inglaterra la prisión perpetua puede ser impuesta como una efectiva privación de la libertad por el tiempo de vida del condenado. Al momento de imponer el castigo al culpable se puede determinar el tiempo a partir del cual la persona podría acceder a la libertad condicional (Tariff). Pero en algunos casos excepcionales por su gravedad esta posibilidad puede ser prohibida, convirtiendo así la prisión en cadena perpetua. Luego de la abolición de la pena de muerte para los homicidios en 1965, se dispuso que el castigo para esos delitos sea el de prisión perpetua (Murder, 1965). La posibilidad de ser liberado condicionalmente depende de lo que se haya dispuesto al momento de imponer la condena (Parliament assembled, 2000), la cual determina que el juzgador puede decidir, basándose en la gravedad del crimen (Juliano y Ávila, 2012). Ahora bien, la cadena perpetua (life imprisonment) dura en principio hasta la muerte del condenado.

No obstante, en 1983 apareció el tiempo mínimo de reclusión conocido como (Tariff), el cual es considerado como un período mínimo obligatorio de cadena perpetua, resultado de dividir la duración de esta pena en tres fases: retribución, disuasión y protección de la sociedad y de hacer de las dos primeras fases un tiempo de condena de obligatorio cumplimiento. El tiempo mínimo lo decidían los jueces que podrían obligar eventualmente al cumplimiento íntegro de la cadena perpetua en casos excepcionales.

En el 2003, por medio de una decisión del alto tribunal Justice Criminal la salida de prisión quedó prohibida para los culpables de crímenes múltiples, al igual que para los reincidentes de delitos como homicidio, secuestro o terrorismo. Solo quedó una excepción a este castigo: que el ministro de justicia o la secretaria de Estado decidieran liberar por razones humanitarias al condenado a esta pena por encontrarse en riesgo de fallecer dentro de la prisión por enfermedad grave e incurable. En concordancia con lo anterior, no existe en el mencionado ordenamiento jurídico de Inglaterra la revisión de la condena a cadena perpetua, y por eso la Criminal Justice Act fue calificada por el Tribunal Europeo de Derechos Humanos que era violatoria del artículo 3 de la Convención Europea de Derechos Humanos, que prohíbe la tortura (Gargallo, 2016).

Pues no hay posibilidad de revisión predeterminada, lo cual sucedía antes del 2003. Por otro lado, un crimen penado con cadena perpetua era el cometido por una persona mayor de 21 años. Para quienes no llegaban a esa edad, la ley contempla otra clase de penas, como la detención para proteger la comunidad y prisión para proteger a la comunidad. Estas figuras permiten la posibilidad de excarcelación según el caso. La detención se aplicaba a los delincuentes infractores menores de 18 años de edad y la prisión a quienes oscilan entre 18 y 21 años sucesivamente (Gargallo, 2016). La 
libertad para los sometidos a la detención (detention) y a la prisión (imprisonment) no se otorgaba en un momento estipulado por la ley, sino que se les mantenía bajo medida intramural hasta que la junta de tratamiento penitenciario (Parole Board) autorizara su excarcelación, evidenciando así la irrelevancia de la revisión de la pena de cadena perpetua en Inglaterra y Gales, y también la ausencia de voluntad institucional para rehabilitar al condenado.

\section{España}

Dentro del primer Código español de 1822 no se contempla la cadena perpetua, pero sí existían cinco (5) clases de castigo de carácter perpetuo: privación de oficio, destierro, galeras/arsenales y la privación de salario. Las penas de cadena perpetua y reclusión perpetua se consideraban las inmediatamente inferiores en grado a la establecida como pena de muerte para los delitos incluidos en el Código Penal de 1848. Estas condenas eran particularmente por delitos graves contra el Estado y el orden público. Por ejemplo, apoyar a otras potencias en la guerra contra España o provocar rebeliones internas (Gargallo, 2016).

Su implementación comenzó en el Código de $1848^{5}$ tras la pena de muerte, que era la pena más grave del ordenamiento jurídico. Se establecía que los condenados debían cumplirla en lugares especiales, ubicados en su mayoría en las afueras de las grandes ciudades. La condena a cadena perpetua llevaba consigo la obligación de realizar trabajos a favor del Estado. Estas penas representaban una novedad en el ordenamiento jurídico penal español, ya que las normas anteriores a la implantación imponían la pena de presidio con una duración máxima de 12 años, por lo cual introducían una importante modificación en la duración de las penas de prisión (Castro, 1848).

De igual forma, en el Código Penal de 1850 también figuró esta pena con las mismas reglas de cumplimiento que en el Código Penal de 1848. Por su parte, en el Código Penal de 1870 se incluyeron algunos cambios en la aplicación de las penas de cadena perpetua y reclusión perpetua, de nuevo incorporadas en la codificación de la pena de muerte en busca de mejorar las condiciones de condena de los presos de cadena perpetua (Gargallo, 2016). Adicionalmente, en el mencionado Código se contemplaba el indulto de la pena de cadena perpetua tras el cumplimiento de 30 años, salvo que por la conducta grave u otras circunstancias los condenados a la misma no fueran merecedores del indulto. El cumplimiento se prolongaba a su vez a 40 años si la pena de cadena perpetua resultaba como consecuencia de una pena superior impuesta con anterioridad.

El Código Penal de 1928 ya no establecía la pena de cadena perpetua. Su modificación mediante el Código de 1932 trajo consigo un gran avance al abolir todas las penas perpetuas y la pena de muerte. A su vez, el Código de 1932 dispuso

5 Dentro del artículo 24 del citado Código de 1848, aparecía la pena de cadena perpetua en segundo lugar, tras la pena de muerte, en la escala de penas infames, seguía la de reclusión perpetua y relegación perpetua. 
una readaptación del Código Penal de 1870, porque es muy parecido al anterior en cuanto a su estructura y contenido. La reforma más fundamental es la supresión formal de la pena de muerte en aras de humanizar las penas y sensibilizar el Código, sustituyéndose la cadena perpetua por la pena de reclusión mayor, con una duración de veinte años (Martín, 2014).

En el sistema punitivo del Código Penal de 1995, vigente en la actualidad, se encuentran las penas privativas de la libertad tales como la prisión; localización permanente y responsabilidad personal subsidiaria, pago de multa, entre otras. De esta manera quedó derogada la norma implementada por las normas anteriores para recurrir a penas privativas de la libertad tales como presidio mayor y menor, prisión mayor y menor, reclusión entre otras. Es significativo que, en la pena de prisión, se fija su duración que va desde tres (3) meses a (20) veinte años como máximo, salvo las excepciones que contenga el código. De conformidad con lo anterior, se entiende que en la actualidad en la legislación española no existe la pena de cadena perpetua. Sin embargo, cabe la posibilidad de que, atendiendo a las circunstancias del recluso (edad, salud...) pueda llegar a darse eventualmente una reclusión perpetua dependiendo de la pena interpuesta en cada caso concreto (Martín, 2014).

\section{Singapur, Japón y República Popular de China}

En Singapur se encuentra vigente la condena a muerte. Aun así, también se establece como posible la prisión perpetua como alternativa frente a la primera. Se contempla para delitos como agresión al presidente, genocidio, rebelión, instigación al suicidio, infanticidio, entre otros. Las penas se encuentran tipificadas en el artículo 54 del Código Penal de Singapur como "prisión cuya duración es igual a la vida natural de la persona” (Juliano y Ávila, 2012). En Japón se encuentra legislada en el artículo 9 del Código Criminal establecida en dos modalidades: con o sin trabajo. En el artículo 18 se contempla que un condenado a prisión perpetua puede ser condenado a prisión perpetua revisable y puede ser liberado condicionalmente después de 10 años de cumplida su condena. Lo anterior se encuentra previsto como alternativa a la pena de muerte específicamente para delitos tales como el homicidio o rebelión.

Por último, en la República Popular de China se aplica la pena de muerte como castigo más severo, al igual que se contempla en su legislación la prisión perpetua como pena principal y admite la libertad condicional luego de que el condenado haya permanecido mínimo 10 años en prisión. Se encuentra previsto para delitos tales como rebelión, homicidio, terrorismo, delitos políticos, etc. ${ }^{6}$

6 Criminal law of the people's Republic of China (Adopted by second session of the fifth national people's Congress on July 1, 1979 and amended by the fifth session of the eighth national people's Congress on march 14, 1997). 


\section{Estados Unidos}

Debido a la variedad de legislación criminal que posee Estados Unidos por su organización federal, se pueden encontrar en los diferentes Estados que integran el país prácticamente todas las formas de prisión perpetua. (Labardini, 2010) Actualmente casi todos los Estados cuentan con la posibilidad de imponer penas perpetuas sin posibilidad de libertad condicional (life imprisonment without parole), con la única excepción del Estado de Alaska. La extendida vigencia de este tipo de condenas encuentra su justificación jurídica, en que han sido estudiadas como una alternativa más "humana" y "garantista" que las penas de muerte, también vigentes en ese país.

Una situación muy controvertida en Estado Unidos es la posibilidad de condenar a personas menores de edad a castigos perpetuos, sin posibilidad de liberación condicional. Este tipo de castigos son aplicables en diversos estados (en Washington por ejemplo se había declarado constitucionalmente válida esta posibilidad) (Supreme Court of Kansas, 247 Kan. 79, 1990) Realidad descrita en el informe de Human Right Watch, donde se denunciaban los casos en los cuales se sentenciaban a menores con prisión perpetua hasta su muerte (Juliano y Ávila, 2012).

\section{Brasil}

Prohíbe constitucionalmente la pena perpetua. En su apartado sobre los derechos y garantías constitucionales, en el artículo quinto (5) expresamente rechaza las penas de carácter perpetuo 7 . Igualmente, en su Código Penal se impone un límite de 30 años para cualquier pena privativa de la libertad. De igual forma, el Supremo Tribunal Federal ha negado solicitudes de extradición cada vez que considera que la legislación del país requirente no respeta los Derechos Humanos, razón por la cual el indulto de la pena de prisión perpetua se considera una condición necesaria a fin de extraditar a personas desde Brasil (Juliano y Ávila, 2012).

\section{Chile}

El presidio perpetuo está solamente contemplado para delitos graves, tales como el hurto con resultado de homicidio, violación de menores con resultado de muerte, secuestro con agravantes, además de los delitos de traición a la patria y deserción en tiempos de guerra (Juliano y Ávila, 2012). El artículo 32 bis del Código Penal chileno, establece que el presidio perpetuo implica la privación de la libertad de por vida y que solo se puede conceder la libertad condicional una vez transcurridos los (40) cuarenta años de pena efectiva y habiendo cumplido el condenado con las normas y requisitos que requieren su otorgamiento ${ }^{8}$.

7 Constituicao da República Federativa do Brasil de 1988, art. 5 inc. XLVII: "ñao haverá penas: a) de norte, salvo em guerra declarada, nos termos do art. 84, XIX; b) de carácter perpétuo; c) de trabajos forcados; d) de banimento; e) cruéis".

8 En el artículo 32 del Código Penal de Chile se señala lo siguiente: "La imposición del presidio perpetuo calificado incluye la privación de la libertad del condenado de por vida, bajo un régimen especial 
Por su parte, las penas de presidio se encuentran reguladas a su vez en el artículo 21, el cual establece como presidio perpetuo calificado, presidio perpetuo, reclusión perpetua, presidio mayor, reclusión mayor, relegación perpetua, confinamiento mayor, extrañamiento mayor, relegación mayor y presidio menor para las penas de delitos simples. De igual forma, en el artículo 27 del Código Penal chileno se tipifica que las penas de presidio, reclusión y relegación perpetuos, llevan consigo la inhabilitación absoluta perpetua para cargos y oficios públicos y derechos políticos por el tiempo de vida de los condenados y la de sujeción a la vigencia de la autoridad por el máximum que establece el mencionado Código.

\section{Perú}

La Constitución del Perú no menciona las penas a perpetuidad, su Código Penal, luego de diversas reformas, mantiene la previsión de la cadena perpetua como pena privativa de la libertad ${ }^{9}$ para algunos delitos contra la propiedad o la libertad sexual, entre otros. Sin embargo, el 3 de enero del 2003, el Tribunal Constitucional resolvió que la prisión perpetua o vitalicia sin fecha de liberación es inconstitucional debido a que los fines de "reeducación, rehabilitación y reincorporación" del régimen penitenciario obligan al legislador a prever una fecha en la que la sanción habrá de concluir, lo que posibilitará al individuo encarcelado reincorporarse nuevamente a la sociedad (Labardini, 2010). Lo anterior obligó a que se legislara al respecto, y actualmente la cadena perpetua puede ser revisada de oficio o a petición de parte por un juez, luego de 35 años de cumplimiento de la pena. En otros países de América Latina, como Venezuela, el Salvador ${ }^{10}$ y Costa $\operatorname{Rica}^{11}$ prohíben a nivel constitucional las penas a perpetuidad. Por su parte Nicaragua fija un límite de 30 años para cualquier clase de pena privativa de la libertad ${ }^{12}$.

de cumplimiento que se rige por las siguientes reglas:

1. No se podrá conceder la libertad condicional sino una vez transcurridos cuarenta años de privación de la libertad efectiva, debiendo en todo caso darse cumplimiento a las demás normas y requisitos que regulen su otorgamiento y revocación. 2. El condenado no podrá ser favorecido con ninguno de los beneficios que contemple el reglamento de establecimientos penitenciarios, o cualquier otro cuerpo legal o reglamentario que incluya su puesta en libertad, aun en forma transitoria".

9 Art. 29 Código Penal del Perú, según Decreto Legislativo No. 982, publicado el 22/07/2007: "Duración de la pena privativa de la libertad. La pena privativa de la libertad puede ser temporal o de cadena perpetua. En el primer caso, tendrá una duración mínima de (2) dos días y una máxima de (35) treinta y cinco años".

10 Constitución Política de la República de El Salvador de 1983, actualizada hasta reformas de introducida por ACLARAR el DL, No. 56, del 06/07/2000, Art. 21, Párr. No. 2 "Se prohíbe la prisión por deudas, las penas perpetuas, las infamantes, las prescriptivas y toda especia de tortura".

11 Constitución Política de la República de Costa Rica, Art. 40: "Nadie será sometido a tratamientos crueles o degradantes, ni a penas perpetuas, ni a la pena de confiscación. Toda declaración obtenida por medio de violencia será nula".

12 Constitución Política de la Republica de Nicaragua de 1987: "La pena no transciende de la persona del condenado. No se impondrá pena o penas que aisladamente o en conjunto, duren más de 30 años". 


\section{ANÁLISIS JURISPRUDENCIAL}

En varios países se contempla la prisión perpetua, la cual constituye una de las más graves en la escala penal después de la pena de muerte. En algunos países de la Unión Europea no se acepta la cadena perpetua, con una duración indeterminada, para toda la vida del condenado, porque sería contraria al principio de humanidad de las penas y pasa a denominarse cadena perpetua revisable. Se establecen en la legislación diversos mecanismos para convertirla en una pena temporal: por revisión de la condena, por concesión del indulto, de la libertad condicional o la suspensión de la ejecución. El período de revisión varía de unos países a otros. En Alemania, por ejemplo, se puede suspender la ejecución cuando el condenado ha cumplido 15 años, siempre y cuando concurran unos determinados requisitos. La Sentencia del Tribunal Constitucional Alemán del 21 de junio de 1977 estableció que es inconstitucional una pena de prisión perpetua sin posibilidad de liberación por ser contraria a la dignidad humana. Esta Sentencia declara la incompatibilidad también de 30 o 40 años de prisión, se establecen reglas de liberación anticipada en el artículo $57^{\mathrm{a}} \mathrm{STGB}$, que se encuentran seguidas a la libertad vigilada durante 5 años tras haber cumplido como mínimo 15 años en prisión. También se prevé la revisión a los 15 años en Australia y Suiza.

Por su parte, en Italia, la prisión perpetua, denominada “L'ergastolo", establece la concesión de la libertad condicional a los 26 años o también puede terminar su cumplimiento por la concesión de indulto, la gracia o la amnistía. Contempla eventualmente la concesión de la libertad condicional si el reo se ha beneficiado del indulto o la amnistía de forma total o parcial. En Francia se puede aplicar la suspensión a prueba cuando se trate de un delito o crimen contra el derecho común. Se establece la revisión con carácter general a los 18 años de cumplimiento y en casos excepcionales, el tribunal puede decretar que dicha revisión tenga lugar a los 22 años $^{13}$ (Cuerda, 2011).

En Inglaterra y Gales la prisión perpetua admite la posibilidad de obtener la libertad condicional pasado un tiempo mínimo establecido por el juez. Transcurrido ese tiempo, un órgano público independiente decide sobre la concesión basado en un juicio de peligrosidad. En Gran Bretaña tiene lugar de 20 a los 25 años, en Grecia a los 20 años, en Dinamarca a los 12 años y en Irlanda a los 7 años. El Consejo de Europa recomienda limitar la duración de las penas privativas de la libertad ${ }^{14}$. El Estatuto de Roma establece que la prisión no podrá exceder de 30 años. Excepcionalmente, podría imponerse la prisión vitalicia cuando "lo justifique la extrema gravedad del crimen y las circunstancias personales del condenado". El Tribunal Penal Internacional

13 En Francia, en el 2008 se aprobó la Ley de Retención de Seguridad que permite a los jueces mantener en prisión a aquellas personas que habiendo cumplido su condena se consideran peligrosas. En el 2011 se incluyó entre los delitos que podían ser castigados con la pena de prisión perpetua los asesinos de personas depositarias de la autoridad pública cometidos con premeditación, por una banda organizada, introducción motivada por el asesinato de un policía francés por la banda terrorista ETA.

14 Estatuto de la Corte Penal Internacional, art.110. 
permite, en casos de prisión perpetua, que se conceda la libertad condicional tras 25 años de cumplimiento de la condena (Serrano, 2012).

\section{Tribunales Internacionales}

\section{Tribunal de Casación Penal de Argentina}

El día 16 de junio del 2009, el Tribunal de Casación Penal de la Provincia de Buenos Aires resolvión ${ }^{15}$, que la pena perpetua (sin límite temporal alguno) es contraria a la normativa constitucional. Veamos un caso: El penado cumplía 44 años de encierro por una condena a reclusión perpetua, más la accesoria de reclusión por tiempo indeterminado y declaración de reincidencia, por lo cual se solicitó su libertad por cumplimiento de la pena. Esta petición fue rechazada inicialmente, pero al presentar el recurso, el Tribunal Argentino se pronunció de la siguiente manera:

El Código Penal argentino ha establecido límites temporales, para que los condenados con esta especie de pena, gocen del beneficio de la libertad (arts. 13, 53 y 55 cód. Penal-Según Ley 21338), aun en caso de resultar multireincidentes o de serles impuesta la pena accesoria que prevé en artículo 52 del mencionado código. Conforme al caso concreto, que si la persona resulta en posición de solicitar la libertad transcurridos 20 años de encierro, y las reglas de conducta abrían de extenderse por 5 años más, entonces la pena, pese a su calificación de "perpetua" tenía en realidad un plazo máximo de duración de 25 años, pena que no implica necesariamente un encierro de por vida".

Cumplido el plazo "ut-supra" señalado y de conformidad con lo dispuesto en el artículo 53 del Código Penal argentino, transcurridos 5 años del cumplimiento de la reclusión accesoria el tribunal que hubiere dictado la última condena o impuesto la pena única estaba facultado para otorgarle la libertad condicional (situación que no se produjo en el caso concreto). Así mismo, el artículo citado establece que luego de 5 años de obtener la libertad condicional, el condenado podía solicitar su libertad definitiva al tribunal que, para el caso en mención, se le concedió (Juliano y Ávila, 2012).

\section{Tribunal Constitucional del Perú}

En enero del 2003, el Tribunal Constitucional peruano se pronunció sobre la inconstitucionalidad de la cadena perpetua tal como se encuentra prevista en la legislación de ese país. Los actores cuestionaban la validez constitucional de la aplicación de la pena de cadena perpetua por considerarla incompatible con el artículo 5.2 de la Convención Americana sobre Derechos Humanos. El Tribunal sostuvo que al tener la pena como fines la reeducación, rehabilitación y reincorporación, no era constitucionalmente válido que se previera como sanción una pena sin fecha de culminación. De allí que fuese obligatorio que el legislador determinara una fecha de

15 Tribunal Casación penal, Buenos Aires, Sala 3", 16/06/2009. "Castaño, Oscar A". 
cumplimiento de la pena, de tal manera que el condenado pueda reincorporarse a la vida en sociedad. El Tribunal Peruano se pronunció de la siguiente manera:

A juicio del Tribunal, de las exigencias de reeducación, rehabilitación y reincorporación como fines del régimen penitenciario se deriva la obligación del legislador de estipular una fecha de culminación de la pena, de manera tal que permita que el condenado pueda reincorporarse a la vida en sociedad. Si bien el legislador cuenta con una amplia libertad para configurar los alcances de la pena, sin embargo, tal libertad tiene un límite de orden temporal, directamente relacionado con la exigencia constitucional de que el penado se reincorpore a la sociedad. Sin embargo, a juicio del Tribunal Constitucional, el establecimiento de la pena de cadena perpetua es contrario a los principios de Dignidad Humana y de la libertad.

En primer lugar, es contraria al principio de libertad, ya que si bien la imposición de una pena determinada constituye una medida que restringe la libertad personal del condenado, es claro que, en ningún caso, la restricción de los derechos fundamentales puede terminar con la anulación de la libertad de forma definitiva del ser humano. En segundo lugar, se considera que detrás de las exigencias de reeducación, rehabilitación y reincorporación como fines del régimen penitenciario, también se encuentra necesariamente una concreción del principio de Dignidad Humana inherente a la persona, constituyéndose en un límite para el legislador penal.

Lo anterior hace referencia a la esperanza del condenado de lograr la libertad y a la calidad de ser humano sujeto de derechos y de protección. La cadena perpetua es por sí misma contraria a la naturaleza del ser humano, en un Estado social de derecho no se encuentra justificación para aplicarla. El Tribunal concluyó en el caso en mención que, por asimilación al Estatuto de la Corte Penal Internacional, el establecimiento de la pena de cadena perpetua solo es inconstitucional si no se prevén mecanismos temporales de excarcelación, vía los beneficios penitenciarios u otras que tengan por objeto evitar que se trate de una pena sin límite de tiempo. Si en un plazo razonable el legislador no dictase una ley en los términos exhortados, por la sola eficacia de esta sentencia, al cabo de 30 años de iniciada la ejecución de la condena, los jueces estarán en la obligación de revisar las sentencias condenatorias en Perú (Juliano y Ávila, 2012).

\section{Suprema Corte de Justicia de México}

En el 2001, la Suprema Corte de Justicia de la Nación SCJN del país mexicano estableció que la prisión vitalicia debía considerarse inconstitucional, dado que, de conformidad con su artículo 22 , dicha práctica constituye una pena inusitada, la cual se ha entendido por su acepción constitucional "como aquella que ha sido abolida por inhumana, cruel, infamante y excesiva o porque no corresponde a los fines punitivos" (prisión vitalicia, constituye una pena inusitada de las prohibidas, 2001), pues el propósito del sistema penitenciario consistía en la readaptación social y la reeducación de los internos. 
Lamentablemente, con posterioridad, en 2005 la Suprema Corte se alejó de ese criterio y estableció que la prisión vitalicia era constitucionalmente valida al estudiar el artículo 27 del Código Penal del estado de Chihuahua ${ }^{16}$, que prevé la acumulación de penas de prisión efectiva aun cuando con ello se exceda el máximo de la sanción prevista individualmente, tratándose de homicidio doloso y secuestro en contra de mujeres o menores de edad, con lo cual en la práctica pueden aplicarse penas que superen los cien años de reclusión (Juliano y Ávila, 2012).

En acción de inconstitucionalidad 20/2003 solicitaron la invalidez del Decreto número 790/03, mediante el cual se modificaron diversos artículos del Código Penal del estado de Chihuahua. Los accionantes manifestaban que el artículo en referencia era violatorio de los artículos 14, 16, 18, 22, 41 y 133 de la Constitución Política de los Estados Unidos Mexicanos, debido a que permitía la prisión vitalicia (Pérez, 2006). También, en Sentencia P./J. 1/2006, publicada en el Semanario Judicial de la Federación y su Gaceta, Tomo XXIII, febrero de 2006, página 6, se manifestó que el Tribunal de la Suprema Corte de Justicia había realizado una interpretación del concepto de pena inusual a la ubicada en la Constitución:

Prisión vitalicia no constituye una pena inusitada de las prohibidas por el artículo 22 de la Constitución Política de los Estados Unidos Mexicanos: La acepción de pena inusitada a que se refiere el precepto constitucional citado se constriñe a tres supuestos: a) Que tenga por objeto causar en el cuerpo del sentenciado un dolor o alteración física; b) Que sea excesiva en relación con el delito cometido; que no corresponda a la finalidad que persigue la pena, o que se deje al arbitrio de la autoridad judicial o ejecutora su determinación al no estar prevista en la ley pena alguna exactamente aplicable al delito de que se trate; y, c) Que siendo utilizada en determinado lugar no lo sea ya en otros, por ser rechazada en la generalidad de los sistemas punitivos. En congruencia con lo anterior, se concluye que la pena de prisión vitalicia no se ubica en alguno de los referidos supuestos, ya que si bien inhibe la libertad locomotora del individuo, no tiene por objeto causar en su cuerpo un dolor o alteración física. Por otra parte, es importante señalar que el hecho de que la prisión vitalicia no tenga como consecuencia que el reo se readapte a la sociedad, dado que éste no volverá a reintegrarse a ella, tampoco determina que sea una pena inusitada, toda vez que el constituyente no estableció que la de prisión tuviera como única y necesaria consecuencia la readaptación social del sentenciado, ni que ese efecto tendría que alcanzarse con la aplicación de toda pena, pues de haber sido esa su intención lo habría plasmado expresamente.

16 Artículo 27. Código Penal del Estado de Chihuahua (México): La prisión consiste en la privación de la libertad, que podrá ser de (3) tres meses a (60) sesenta años, recluyendo al sentenciado a la institución que designe el Ejecutivo del Estado. Tratándose del delito de homicidio doloso en perjuicio de mujeres o de menores de edad, o del delito de secuestro, deberá imponerse pena por cada delito cometido aún y cuando con ello se exceda el máximo de la pena de prisión. 
No obstante, la Suprema Corte de Justicia resolvió declarar la constitucionalidad de los artículos 127 y 136 del Código Penal chihuahuense, por lo tanto, se aleja de los criterios jurisprudenciales que pocos años antes habían aprobado. Las primeras sentencias condenatorias a prisión vitalicia en Chihuahua son del 22 de diciembre de 2010: Alfredo Cruz Guzmán, de 18 años fue sentenciado a cadena perpetua por secuestro y robo de vehículos. Y según Sentencia del 24 en febrero de 2011, una mujer, Erika Alonso, de 28 años, fue sentenciada por secuestro y homicidio a más de 100 años de prisión (Espinosa, 2012).

\section{Tribunal Constitucional Federal Alemán}

El Tribunal Constitucional Federal Alemán, mediante Sentencia BVerFge 45$187^{17}$ revisó la cadena perpetua prevista para el delito de homicidio, para establecer si era compatible o no con el derecho a la dignidad humana y con los demás derechos fundamentales promulgando lo siguiente:

De acuerdo a la situación actual de los conocimientos no se puede asegurar que la pena de reclusión perpetua, conforme a lo previsto en la ley penal y en consideración de prerrogativa de gracia, lleve forzosamente a daños de tipo psicológico y físico que lesionen la dignidad del hombre.

En la misma sentencia manifestaba que existe una limitación para que esta clase de pena se mantenga acorde con los preceptos constitucionales:

A los presupuestos de cumplimiento de una pena dentro del marco de la Dignidad Humana, pertenece en que los condenados a prisión perpetua tengan al menos una oportunidad de gozar nuevamente de la libertad. La posibilidad de un indulto no es por sí solo suficiente, antes el principio del Estado de Derecho ofrece los presupuestos bajo los cuales la ejecución de una pena de prisión perpetua puede suspenderse, así como para reglamentar el proceso aplicable para tal efecto.

\section{Tribunal Europeo de Derechos Humanos}

El 9 de julio del 2013, la gran sala del Tribunal Europeo de Derechos Humanos - TEDH dictó un fallo trascendental (caso Vinter) directamente relacionado con el control de las penas perpetuas. El caso en mención revisa de forma conjunta tres recursos presentados por los ciudadanos británicos Vinter, Bamber y Moore, cuyas demandas fueron consideradas de forma simultánea y rechazada por el Convenio Europeo para la Protección de Derechos Humanos (CEDH) por la sección 4 de (TEDH). La gran sala admitió la revisión del caso a su consideración emitiendo un pronunciamiento final que confirmaba la violación del artículo 3 del (CEDH)

17 Jurisprudencia del Tribunal Constitucional Federal Alemán. Extractos de las sentencias más relevantes compiladas por Jürgen Schwabe, fundación Kond-rad-Adenauer-Stiftung V, 2009. Recuperado de www.kas.de/rspla-mex/es/publications/16817. 
relativo a la prohibición de la tortura, tratos inhumanos y degradantes por la manera como una de las modalidades de prisión perpetua denominada "whole life" se aplicó según la legislación inglesa vigente (Landa, 2015).

Los casos puestos en consideración del Tribunal son paradigmáticos de criminalidad muy grave, empezando por Vinter quien había sido condenado a cadena perpetua por asesinar a un colega de trabajo en 1996, al que siguió una vez liberado condicionalmente, el de su mujer en 2008 mediante una acción combinada de estrangulamiento y apuñalamiento posterior. Por su parte, Bamber asesinó en 1985 a sus padres, su hermana adoptiva y a los dos hijos menores de esta. Por ello no solo se le aplicó la cadena perpetua, sino también la orden de que fuera "para toda la vida". El último de los demandantes Moore, también fue condenado por asesinato múltiple, en este caso de cuatro homosexuales, motivado al parecer por un ánimo de obtener así satisfacción sexual; las víctimas fueron apuñaladas repetidamente una a una con un cuchillo de combate comprado para tal efecto. La condena a pena perpetua fue solicitada y aplicada para toda la vida.

En el caso Vinter, desde la perspectiva del Tribunal Europeo de Derechos Humanos, no se discute la imposición de la pena por su eventual desproporción, sino desde la óptica de las condiciones de su legitimidad articulada sobre dos ejes esenciales: en primer lugar, la necesidad de que exista una expectativa de puesta en libertad, y en segundo lugar, de que haya una posibilidad de revisión en la pena. La pena perpetua, por tanto, debe articularse de manera que exista un derecho a la esperanza (expectativa de liberación), acompañada de mecanismos efectivos de revisión de facto. Lo anterior, se debe someter a diversos estándares de control como por ejemplo que la pena perpetua sea "reducible de iure", pero también "de facto", de ello se deriva una obligación procesal: que exista un mecanismo de revisión sujeto a algún tipo de plazo para su activación; en segundo lugar, que exista un motivo legítimo de política criminal (Landa, 2015).

El tribunal inició sus conclusiones generales resaltando que la función del mecanismo de revisión consiste en permitir que las autoridades nacionales evalúen:

(...) si los cambios experimentados en la persona condenada a cadena perpetua son tan importantes y que se ha hecho tales progresos hacia la rehabilitación en el transcurso de cumplimiento de la condena, que el mantenimiento de la pena de prisión no está ya justificado en ningún motivo legítimo de política criminal.

Por último, se argumenta la seguridad jurídica que otorga el mecanismo de revisión de la cadena perpetua, estableciendo como precedente la doctrina Vinter, la cual establece los criterios de revisión de las penas, articulando los mecanismos de control de conformidad con el artículo 3 del CEDH. 


\section{Tribunales nacionales}

\section{Corte Constitucional}

La línea jurisprudencial que ha implementado la Corte Constitucional relacionada con la prohibición constitucional de la cadena perpetua tiene su enfoque en los fines de la pena, señalando en la Sentencia C-596 de 1992 que establece que la "la pena es un recurso jurídico-político encaminado a la protección del grupo social por medio de la disuasión del ciudadano frente a la conducta delictuosa y del castigo de los delincuentes". Cabe destacar que frente a la teoría de la retribución, la Corte afirmó que es violencia institucional ejercida mediante penas crueles, inhumanas y degradantes que no conducen a ninguna utilidad preventiva. Aunado a lo anterior, en la Sentencia C-070 de 1996 la Corte establece que "le está vedado, por voluntad expresa al constituyente, establecer la pena de muerte, destierro, prisión perpetua o confiscación, así como someter a cualquier persona a torturas, tratos o penas crueles, inhumanos o degradantes" (Constitución, 1991). Por otra parte, en el ejercicio de la facultad punitiva del Estado, el legislador debe propender por la realización de los fines sociales del Estado, entre ellos, los de garantizar la efectividad de los principios, derechos y deberes consagrados en la Constitución que asegure la vigencia de un orden justo (Corte Constitucional, C-070, 1996).

En el mismo sentido, estableció que

Sólo son compatibles con los derechos humanos penas que tiendan a la resocialización del condenado, esto es a su incorporación a la sociedad como un sujeto que la engrandece, con lo cual además se contribuye a la prevención general y la seguridad de la coexistencia, todo lo cual excluye la posibilidad de imponer la pena capital.

Agregando así, la pena de prisión perpetua (Corte Constitucional, C-144, 1997). En cuanto a las penas crueles e inhumanas, como la perpetua, la Corte señala que es un contrasentido cuando se repara la normatividad penal y el desarrollo jurisprudencial le otorga a la prevención especial, como recuperación del sujeto que delinquió, que la engrandece y puede ser nuevamente útil a la sociedad. Al considerar que el Estado constitucional dentro de la órbita de protección de la sociedad, y de prevención general, debe tener siempre presente y potenciar la dignidad humana en todos los ámbitos de la vida, incluyendo el derecho sancionatorio, punto en el cual se articula la prevención general con la especial, por la eliminación de penas crueles y violatorias de los derechos fundamentales y ofrecimiento de alternativas al comportamiento desviado que propugnen por la resocialización. Estas fronteras al ejercicio libre de los derechos y a la facultad coercitiva deben respetar al infractor, estar guiadas en todo momento por la libertad, igualdad, razonabilidad, proporcionalidad, necesidad y culpabilidad como expresión del respeto constante por los derechos humanos (Corte Constitucional, C-806, 2002). 
En el salvamento de voto de la Sentencia C-1212 del 2001 de los magistrados Uprimny Yepes y Escobar Gil decidieron declarar inconstitucionales las penas de carácter perpetuo bajo el siguiente argumento:

El derecho a no ser sometido a penas imprescriptibles tiene como objetivo permitir la resocialización de la persona condenada. La regla según la cual no existen penas imprescriptibles es una garantía constitucional de que el Estado va a atender la función resocializadora de la pena. Por Otra parte, esta función resocializadora está fundada en el valor primordial sobre el cual está fundamentado nuestro Estado de Derecho: la Dignidad Humana que no se pierde por la comisión de un delito. Presumir que una persona que ha cometido un delito y ha pagado una condena no ofrece una garantía suficiente de moralidad es estigmatizarla, desconociendo el carácter resocializador que consagra la Constitución. En esta medida teniendo en cuenta la estirpe constitucional de la imprescriptibilidad de las penas como garantía de su carácter resocializador, en consonancia con el principio prolibertate, es natural que esta prohibición cubra también las penas perpetuas.

En cuanto al principio constitucional de proporcionalidad de las penas, la Corte Constitucional en su más reciente jurisprudencia referida al tema, la Sentencia C-397 del 2010 señala que la prisión perpetua desconoce el principio de proporcionalidad de la pena como elemento esencial de un Estado social de derecho al establecer lo siguiente:

La potestad legislativa del Estado no justifica la imposición de medidas por parte del mismo que no sean proporcionales o que atenten contra la Dignidad Humana, por lo que, si bien la intensidad de las medidas debe tener una correspondencia con la gravedad del delito, la imposición de una medida sin límite en el tiempo iría en contra del principio de proporcionalidad de las penas, una de las características inherentes al castigo como medida en el marco del sistema penal, derivada su aplicación de la Dignidad Humana.

\section{Corte Suprema de Justicia}

En la Corte Suprema de Justicia, Sala de Casación Penal se encuentra la jurisprudencia relativa a los fines de la pena, reconociendo y aplicando teorías de la doctrina penal que reconocen la funcionalidad, la retribución y la prevención especial bajo los principios de razonabilidad, proporcionalidad y necesidad. De acuerdo con este precepto constitucional, el Estado tiene el deber de respetar los límites materiales y formales del ius puniendi, ofrecidos sobre la base del ordenamiento democrático, y desechar las justificaciones de las penas a perpetuidad que claramente instrumentalizan al condenado y buscan negarle su protección constitucional en cuanto a los derechos fundamentales inherentes e irrenunciables.

Al respecto, la Corte Suprema señala que "sólo la utilización medida, justa y ponderada del ius puniendi, destinado a proteger los derechos y libertades, es compatible con los valores y fines del ordenamiento jurídico". Lo anterior cancela 
toda posibilidad del establecimiento de penas desproporcionadas; también la clara y recurrente invocación de los principios de proporcionalidad y necesidad como última ratio del derecho penal (Corte Suprema de Justicia, Sala de Casación Penal, SP 33.254, 2013). La Corte Suprema de Justicia en su jurisprudencia sobre los fines de la pena guarda consonancia con el mandato constitucional, del cual evidentemente debe partir el ejercicio del derecho penal, sobre todo frente a las iniciativas de aumento injustificado de sanciones, la prohibición de beneficios. De contrario sensu debe primar el respeto por la protección de los principios de proporcionalidad, razonabilidad y necesidad, los cuales, en la actualidad se encuentran empañados por la incesante política mediática de sancionar punitivamente toda conducta social que afecte bienes jurídicos, lamentablemente con penas muy elevadas y desproporcionadas que buscan en algunos casos impulsar iniciativas populares para lograr la implantación de la cadena perpetua para algunos tipos penales. Al respecto, la Corte Suprema ha señalado lo siguiente:

La pena, para tener legitimidad en un Estado democrático, además de ser definida por la ley, ha de ser necesariamente justa, lo que indica que, en ningún caso puede el Estado imponer penas desproporcionadas, innecesarias o inútiles (Corte Suprema de Justicia, Sala de Casación Penal, SP 33.254, 2013).

\section{POSTURA CRÍTICA Y CONCLUSIONES}

A continuación, se analizan varios temas tratados en el presente artículo sobre los cuales es necesario profundizar. En primer lugar, la prohibición de la prisión perpetua por bloque de constitucionalidad; en segundo lugar, una postura crítica frente a la prisión perpetua y su incompatibilidad con los fines de la pena $\mathrm{y}$, por último, un análisis desde la política criminal y la influencia de los medios de comunicación, a lo que actualmente se conoce como justicia mediática, para impulsar mediante acciones populares la implementación de la cadena perpetua en el ordenamiento jurídico colombiano. Todo esto con la finalidad de precisar unas breves consideraciones sobre por qué se considera que la pena de prisión perpetua en Colombia es inconstitucional.

La anterior afirmación se fundamenta en el precepto constitucional del artículo 12 de la Carta Política, el cual prohíbe la aplicación de cualquier pena cruel, inhumana y degradante, ahora bien, integrándolo por bloque de constitucionalidad haciendo alusión específicamente a la Convención Americana sobre Derechos Humanos en la cual, desde el preámbulo de la misma, se establece el propósito de consolidar un régimen de libertad personal que le permita a cada persona gozar de sus derechos y libertades sin distinciones de ninguna índole, como caso típico, estar sometido a una pena de prisión. A esto se añade, el artículo 5 de la mencionada Convención donde se establece que todas las personas tienen derecho al respeto de su integridad física, psíquica y moral; en consecuencia, no pueden ser sometidas a tratos inhumanos o degradantes, acobijando así a quienes se encuentran privados 
de la libertad. Igualmente, en el Pacto Internacional de Derechos Civiles y Políticos desde su preámbulo se realza el alcance de la dignidad humana, con el fin de que cada persona goce de sus garantías, sin limitaciones por ninguna condición.

Ahora es oportuno extraer que lo dicho en los tratados internacionales sobre derechos humanos crea límites o parámetros de constitucionalidad de las normas y de cualquier intento de reformar la Constitución, para que se cumplan conforme al principio de progresividad. Esto es, con el fin de lograr la mayor protección posible de las garantías, prevaleciendo siempre la normativa que acoja en mayor medida a los condenados, lo cual nuevamente contribuye a la imposibilidad de implantar penas perpetuas. Al igual que el anterior principio se aplicaría el principio de prohibición de regresividad, que opera como límite a la desmejora de la protección en un Estado social de derecho como el colombiano, haciendo imposible su retroceso en materia de imposición de penas. Dentro de este marco ha de considerarse que en ejercicio de la función del ius puniendi, se debe siempre respetar el principio rector y universal de la dignidad humana, ponderándolo de forma razonable y proporcional a la hora de imponer las penas garantizando así el principio pro libertate, en armonía con el principio pro-homine en la ejecución de las penas.

En cuanto a la prisión perpetua y su incompatibilidad con los fines de la pena se podría considerar que no solo vulnera de forma clara el fin de la pena y la prohibición de los tratos degradantes, sino que la cadena perpetua, sea revisable o no, presupone que el delincuente no se puede resocializar, reeducar ni ser útil a la sociedad, ello implica una rotunda negación del eje fundamental de la concepción de la pena: su utilidad y necesidad. Oponiéndose así a los fines esenciales de la pena como lo son la resocialización, reeducación y reinserción social, vulnerando de forma rotunda la dignidad humana del condenado.

Concluyamos este análisis con que, en Colombia, por mandato constitucional, se establece en el artículo 12, que nadie será sometido a penas crueles, inhumanas o degradantes. También, el artículo 34 establece la prohibición de la pena de prisión perpetua. Pero cabe mencionar que dentro del ordenamiento jurídico colombiano existen penas que, aunque de manera expresa no se encuentran establecidas como cadena perpetua en estricto sentido, frente a su aplicación lamentablemente se podrían equiparar. Tal es el caso del delito de feminicidio que cuenta con una pena que puede oscilar entre 20 a 41 años de cárcel; el homicidio en persona protegida, el tráfico de niñas, niños y adolescentes, tienen penas entre 60 a 70 años de prisión; el delito de lavado de activos, el cual, con todos los agravantes que se le han introducido, puede llegar a tener una pena privativa de prisión de 70 años. Según las circunstancias propias de cada caso pueden llegar a superar notablemente la expectativa de vida del condenado, ya que, según las circunstancias de edad y salud, eventualmente se podría convertir en una cadena perpetua, dependiendo de la pena interpuesta en cada caso en particular.

Merece también precisarse para el contexto colombiano la influencia o responsabilidad de los medios de comunicación en impulsar campañas que buscan la imposición de la cadena perpetua para ciertos delitos graves como los que van en contra de la integridad sexual de menores de edad, que en su gran mayoría generan 
un impacto sobre la ciudadanía, los movimientos sociales y la influencia que esto tiene en la implementación de la política punitiva en Colombia a través de iniciativas populares o legislativas impulsadas por casos mediáticos que afectan notablemente los procesos de resocialización. Generalmente, en ocasiones esto podría generar más violencia focalizada, que impide los procesos de reconciliación social.

También cabe destacar que, dicha actividad que efectúa el Estado en su carácter de "Guardián de las necesidades del sistema" (Huertas, 2010) es abiertamente antigarantista y peligroso; contribuye a la venganza, a la imposición de penas arbitrarias y extensas, permea el concepto de justicia estimulando así la inflación punitiva en Colombia. Aquí conviene detenerse un momento a fin de que se debe propender porque en Colombia se tenga como pilar fundamental el garantismo penal y humanista que busque la plena garantía de los derechos fundamentales de los condenados dentro del Estado social de derecho, junto con el esfuerzo de las instituciones estatales para aplicar verdaderamente una justicia humana de ultima ratio, evitando así que nuevas iniciativas, tales como la implementación de la cadena perpetua revisable o no encuentren espacio en la sociedad colombiana.

\section{REFERENCIAS}

Barros, C. (1995). La prisión desde una perspectiva histórica y el desafio actual de los derechos humanos de los reclusos. Instituto Interamericano para los Derechos Humanos. San José: Estudios Básicos de Derechos Humanos.

Castro, Orozco y Ortiz. (1848). Código Penal explicado, para la común inteligencia y fácil aplicación de sus disposiciones. Granada: Imprenta y Librería de D. Manuel Sanz.

Congreso de la Republica de Perú. (1990, octubre 30). Código Penal de la República de Perú [Decreto Legislativo 635 de 1990]. Recuperado de https://www.oas.org/ juridico/mla/sp/per/sp_per_cod_pen.pdf

Congreso Nacional de Chile. (2010, marzo 18). Código Penal de Chile [Ley 2561 de 2010]. Recuperado de https://www.leychile.cl/Navegar?idNorma=1984

Congreso Nacional de México. (2014, noviembre 29). Código Penal del Estado de Chihuahua [Decreto Ley 690 de 2006]. Recuperado de http://www.inegi.org. $\mathrm{mx} / \mathrm{est} / \mathrm{contenidos/proyectos/aspectosmetodologicos/clasificadoresycatalogos/}$ doc/codigos/cp08.pdf

Constituicao da República Federativa do Brasil. (1988). [Cosnt.]. Recuperado de http://pdba.georgetown.edu/Constitutions/Brazil/esp88.html

Constitución Política de la República de Costa Rica. (1949). [Cosnt.] Recuperado de http://www.constitution.org/cons/costaric.htm

Constitución Política de la República de El Salvador. (1983). [Cosnt.]. Recuperado de http://www.constitution.org/cons/elsalvad.htm 
Constitución Política de la Republica de Nicaragua. (1987). [Cosnt.] Recuperado de http://legislacion.asamblea.gob.ni/normaweb.nsf/ (\$All)/06C0DB3B7BCFC75706257307006F6C6D?OpenDocument

Corte Constitucional de Colombia. (1997, marzo 19). Sentencia C-144 [MP. Alejandro Martínez Caballero].

Corte Constitucional de Colombia. (2001, noviembre 21). Sentencia C-1212 [MP. Jaime Araujo Rentería].

Corte Constitucional de Colombia. (2002, octubre 3). Sentencia C-806 [MP. Clara Inés Vargas Hernández].

Corte Constitucional de Colombia. (2010, mayo 25). Sentencia C-397 [MP. Juan Carlos Henao Pérez].

Corte Suprema de Justicia de Colombia. Sala de Casación Penal. (2013, febrero 27). Sentencia 33.254 [MP. José Leónidas Bustos Martínez].

Cuerda, A. (2011). La cadena perpetua y las penas muy largas de prisión: Porqué son inconstitucionales en España. Barcelona: Ed. Atelier.

Echeverri, E. (2003). La detención preventiva y la libertad, seguridad personal en el escenario internacional y nacional. ( $1^{a}$ ed.). Pereira: Ed. Universidad Libre de Colombia.

Espinosa, M. (2012). La cadena perpetua. Una pena sin sentido. La prisión vitalicia en Veracruz. Veracruz: Ed. Letras Jurídicas.

Ferrajoli, L. (1999). Ergástolo y derechos fundamentales. Lima: Ed. Anuario del Derecho Penal.

García, F., y Aguirre, J. (1852). Librería de jueces, abogados y escribanos (vol. 4). Madrid: Ed. José de Vicente y Caravantes.

Gargallo, L., y Olmo, P. (2016). La cadena perpetua en España: Fuentes para la investigación histórica. Grupo de Estudio sobre Historia de la Prisión y las Instituciones Punitivas. Ediciones Universidad de Castilla-La Mancha.

Gómez, G. (2010). Prisión perpetua, Ley 1327 del 2009. Bogotá: Ediciones Doctrina y Ley Ltda.

Goite, M., Medina, A., Fernández, R., Huertas, O., \& Ruiz, A. L. (2016). Globalización, derecho penal mínimo y privación de la libertad a 250 años de la obra cumbre de Beccaria. Revista Prolegómenos Derechos y Valores, 19(38), 109-126.

Huertas, O. (2009). Durkheim: la perspectiva funcionalista del delito en la criminología. Criminalidad, 51(2), 103-115.

Huertas, O. (2010). Anomia, normalidad y función del crimen desde la perspectiva de Robert Merton y su incidencia en la criminología. Revista Criminalidad, 52(1), 365-376.

Huertas, O., López, L.L., \& Malaver, C.M. (2011). La colonia penal de Oriente. Último rezago del positivismo jurídico penal. Diálogos de Saberes, (25), 139-150. 
Hugo, V. (1998). El último día de un condenado. Buenos Aires: Losada.

Juliano, M.A., y Ávila, F. (2012). Contra la prisión perpetua: Una visión histórica y comparada de las penas a perpetuidad. Buenos Aires: Editores del Puerto.

Labardini, R. (2010). Contexto internacional de la prisión vitalicia. Anuario Mexicano de Derecho Internacional. Recuperado de https://revistas.juridicas.unam.mx/ index.php/derecho-internacional

Landa, J. (2015). Prisión perpetua y ley de muy larga duración tras la LO 1/2015: ¿Derecho a la esperanza? Con especial consideración del terrorismo y del TEDH. Revista Electrónica de Ciencia Penal y Tecnología, 17(20). Recuperado de https://dialnet.unirioja.es/servlet/articulo?codigo $=5354904$

Martín, L. (2014). La necesidad político-criminal de la pena de prisión permanente revisable. Tenerife: Ed. Universidad de la Laguna.

Melo, R. (2016, diciembre 9). A propósito de las penas de muerte y cadena perpetua en Colombia, sugeridas por un General de la República. A la luz pública. Recuperado de http://www.alaluzpublica.com/proposito-de-la-pena-de-muertecadena-perpetua-en-colombia-sugeridas-por-general-de-la-republica/

Murder. (1965). Abolition of Death Penalty. The Moder Law Review. Recuperado de http://onlinelibrary.wiley.com/doi/10.1111/j.1468-2230.1966.tb01115.x/pdf

Pascual, L. (2014). La prisión permanente revisable. Un acercamiento a un derecho penal deshumanizado. CLIVATGE, 3. Revistes Cientifiques de la Universitat de Barcelona. ISSN: 2014-6590. Recuperado de http://revistes.ub.edu/index.php/ clivatge/article/view/11981

Parliament Assembled. (2000, mayo 25). Power of criminal courts. Life sentences, $V$. Escocia, Reino Unido.

Pérez, Y. (2006). El cambio de jurisprudencias de la Suprema Corte de Justicia de la Nación sobre la interpretación del concepto de pena inusitada. Universidad de Alicante. Recuperado de http://mmcdesign.com/revista/wp-content/ uploads/2008/03/23b_el_cambio_de_jurisprudencias.pdf

Runyon, T. (1956). Cadena perpetua. Ciudad de México: Editora Latino Americana.

Scimé, F. (1986). Pena y libertad, el fin de la pena como garantía de libertad. Buenos Aires: Pensamiento Jurídico.

Serrano, M. (2012). La prisión perpetua revisable. Revista Jurídica Universidad Autónoma de Madrid, 25. ISSN 1575-720X. Recuperado de https://dialnet. unirioja.es/servlet/autor?codigo $=170564$

Supreme Court of Kansas (1990, July 13). 247 Kan. No. 63,423., Disponible en https:// law.justia.com/cases/kansas/supreme-court/1990/

Tomás, F. (1969). El derecho penal de la monarquía absoluta: (siglos XVI - XVII $X V I I)$. Madrid: Tecnos. 
Torres, M. (2015). La pena de prisión perpetua en Colombia. (Tesis de maestría). Universidad Nacional de Colombia. Recuperado de http://www.bdigital.unal. edu.co/47167/1/699847.2015.pdf

Tribunal Casación Penal, Buenos Aires, Sala $3^{\mathrm{a}}$. (2009, junio 16). Castaño, Oscar A. Zaffaroni, Alagia y Slokar. (2003). Derecho penal (Parte general, $2^{\mathrm{a}}$ ed.). Buenos Aries: Ediar.

Zeno. (1973). Cadena perpetua. Madrid: Ediciones Daimon. 